\title{
New Method for Analyzing Traffic Flow Using Integrated Radar Network System and AIS in Tokyo Bay
}

\author{
Shun LIU *, Hideki HAGIWARA**, Ruri SHOJI** and Hitoi TAMARU**
}

\begin{abstract}
Utilization of Radar Network System for traffic flow observation in Tokyo Bay has been mentioned in former paper. However, radar echoes from vessels which are inside island shade, behind bridge or being covered by the lager ship are not reflected to radar screen. Besides, two ships can't be recognized when they are in close proximity.

With integrating AIS (static and dynamic data) into radar observation and analysis, the above problems have been resolved by using AIS information. Simultaneously, by comparing the radar information with AIS data, the new methods of analyzing and estimating traffic flow have been found. In other words, AIS position can be utilized to automatically track the center of ship image on radar screen; the ship's length by AIS data can be used to improve accuracy of regression formula for estimating ship's length from the size of ship image on radar screen.
\end{abstract}

Keywords: Marine Traffic Engineering, AIS, Radar Network System, Automatic Tracking, Regression Formula of Estimating Ship's Length.

\section{Introduction}

Tokyo Bay is one of the specially congested waters, where about 700 ships sail in and out through Uraga Suido Traffic Route per day. Some serious maritime accidents occurred and influenced safety of maritime traffic and natural environment. In order to effectively prevent maritime accidents and guarantee safety of the traffic route, knowing of traffic characteristics is particularly important in Tokyo Bay.

Up to 2003, radar network system and AIS facility have been installed and some results about traffic characteristics have been introduced in the last study. The software relating to analyzing and estimating traffic flow has also been developed. However, it was insufficient to know the traffic characteristics only by means of radar observation sited at Yokosuka and Kawasaki radar station. The AIS transponder provides much more information than radar is capable of: COG (Course Over the Ground), SOG (Speed Over the Ground), precise ship's position, ship's length and so on. All data of radar image and AIS are available at the monitoring station in the Tokyo University of Marine
Science and Technology (TUMSAT) in real time.

In this paper, by integrating AIS data into radar data, the new functions of analyzing vessel traffic flow are developed. The method to automatically identify and track the center of ship image on radar screen using AIS position is shown. The regression formula for estimating ship's length based on the size of ship image on radar screen is improved and verified with AIS data.

\section{AIS and its character}

According to the SOLAS convention, all the ships of $300 \mathrm{G} / \mathrm{T}$ or more engaged in international voyages must be fitted with AIS by December 2004. Other vessels will also be encouraged to fit the AIS voluntarily. Thus, AIS will act as very important role in effectively monitoring and surveying vessel traffic, together with radar observation system.

In comparison with radar, the AIS receiver offers much more data than radar; in addition to precise speed, course and position obtained from the vessel's GPS, the AIS also provides ship's identification and

* Student Member: Tokyo University of Marine Science and Technology (2-1-6, Etchujima, Koto-ku, Tokyo 135-8533), Sliu@e.kaiyodai.ac.jp 
static data such as ship's length, draft, type of cargo, etc. All information of targets can be obtained more quickly and accurately than radar. In addition, AIS also offers improvement in the areas of target detection, tracking, evaluation and identification. It is not affected by clutter in bad weather. In general, AIS tracking is highly accurate, provided in real-time, capable of instant presentation of target course alterations, not subject to target swap, not subject to target loss in clutter, not subject to target loss due to fast maneuvers and able to look around bends and behind islands.

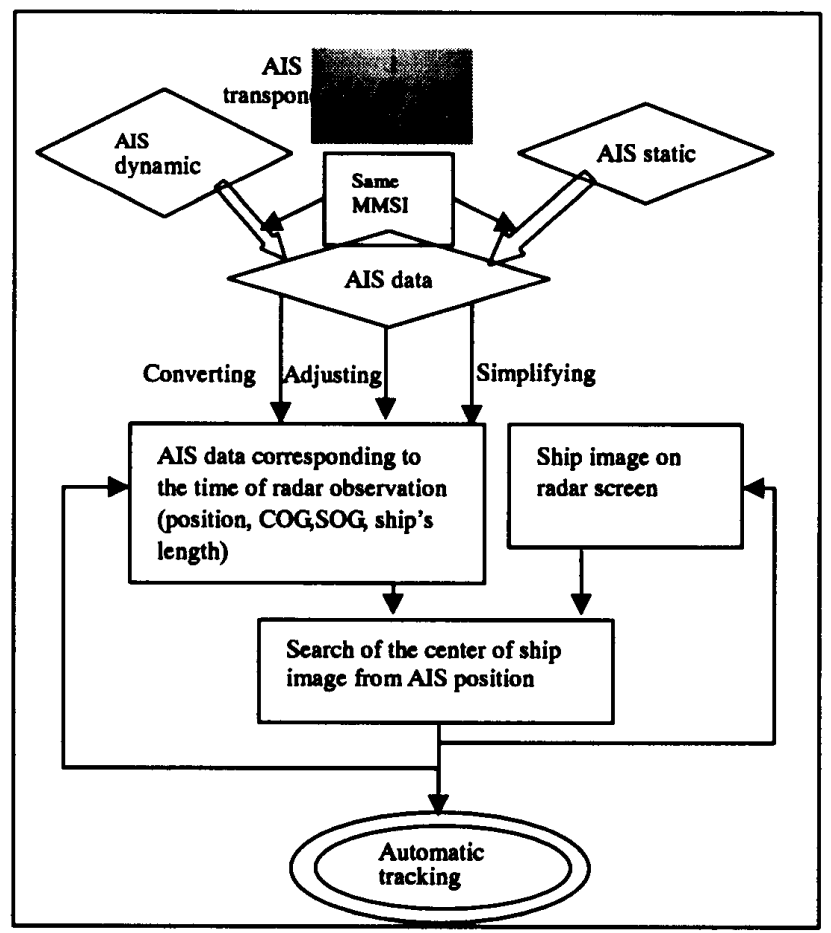

Fig.1 Process for automatically tracking the center of ship image on radar screen from AIS position

To meet the need for maritime traffic observation, the AIS receiver and its antenna were set up in Higashi Ogishima nearby radar station on December 2003. Just like transmitting the radar image, the IP (Internet Protocol) network can propagate the AIS data to AIS data recorder installed in TUMSAT in real time. The intervals of updating data can be designed from 1 second to 10 minutes. When it is operated, we can obtain the static data at updating intervals of 6 minutes (such as MMSI number, call sign, ship's name, ship's length, ship's width, type of ship, etc), and dynamic data at intervals of 2 seconds to 3 minutes (such as UTC, ship position, COG SOG etc) after decoded.
In terms of performances of AIS and radar network system, the new methods for analyzing traffic flow have been developed on the basis of integrated AIS and radar observation in Tokyo Bay. One of functions is shown in Fig.1, namely, the process for automatically tracking the center of ship image on radar screen from AIS position. It will be explained in the following in detail.

\section{AIS data and its application to automatic tracking}

Combining AIS static and dynamic data based on MMSI number should be accomplished as shown in Fig.1. Furthermore, before using AIS position for automatically tracking the center of ship image, it is very crucial to simplify and convert the original AIS data to AIS data corresponding to the time of radar observation. In general, there are 6 to 10 AIS positions within one minute, and after conversion there is only one AIS position at the time of radar observation.

\subsection{Automatic tracking of the center of ship image}

Each pixel constituting a ship image has luminance level which reflects the strength of radar echo. That luminance ranges from 0 to 255 . In this study, the ship image is defined as a set of pixels having luminance of 200 or more. Meanwhile, the above condition is based on the following setting parameters of radar stations; beam width is 0.8 degree $\pm 10 \%$; pulse width is

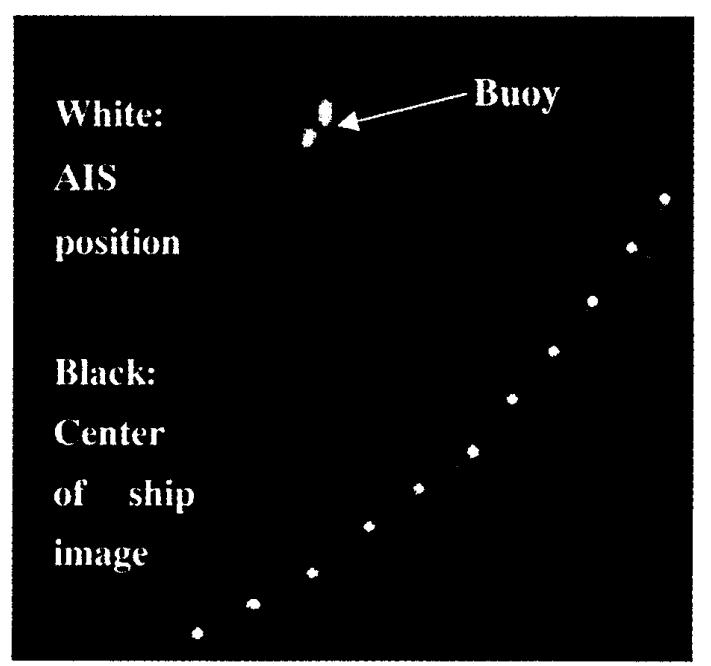

Fig.2 Automatic tracking the center of ship image using AIS position 
$0.8 \mu \mathrm{s}$; gain is $78.1 \%$; FTC is 0 ; STC is $28.6 \%$ (Yokosuka radar station), $55.5 \%$ (Kawasaki radar station).

There are two situations of automatic tracking, namely, AIS position being inside the ship image and outside the ship image. In Fig.2, we can find above situations and will discuss them separately.

\subsubsection{AIS position inside the ship image}

When the pixel's luminance at AIS position is 200 or more, it can be said that AIS position is inside ship image. Fig. 3 indicates this situation. Note that the image has to be confirmed that it is the target of AIS automatic tracking. Thereof, the parameter of AIS data, such as COG and SOG, would be quoted as a means to verify the target.

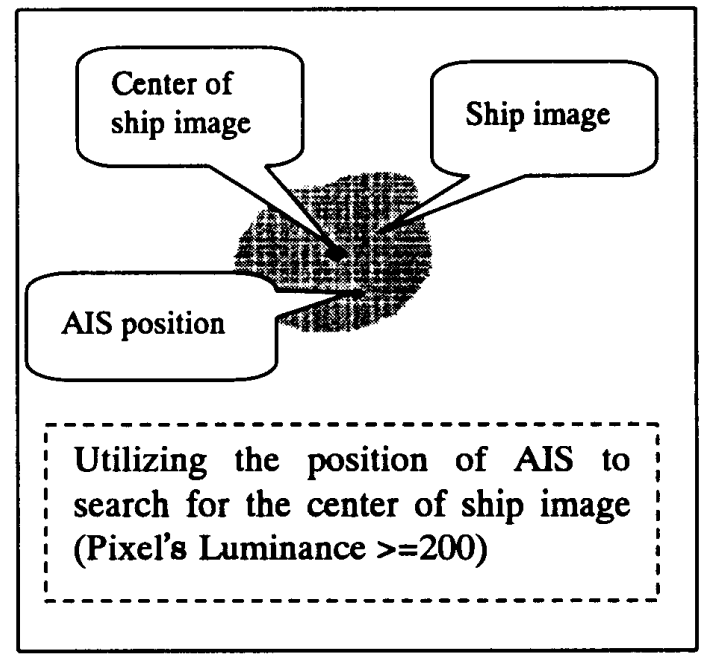

Fig.3 AIS position being inside the ship image

First, regarding the AIS position as origin of coordinates, the pixel's luminance around it is investigated. The pixel increases one by one in vertical axis and horizontal axis, and only if the pixel's luminance is $\mathbf{2 0 0}$ or more, the pixel's coordinates is recorded. By calculating the average coordinates from all coordinates recorded, the center of ship image can be obtained.

Next, speed and course between the center of present ship image and that of previous ship image (one minute ago) are calculated, then, the result are compared with COG and SOG in AIS data. Provided course difference is less than 5 degrees and speed difference is less than $20 \%$, the found ship image can be identified as a target.

\subsubsection{AIS position outside the ship image}

When the pixel's luminance at AIS position is less than 200, this indicates that the AIS position is outside ship image. Fig. 4 shows this situation.

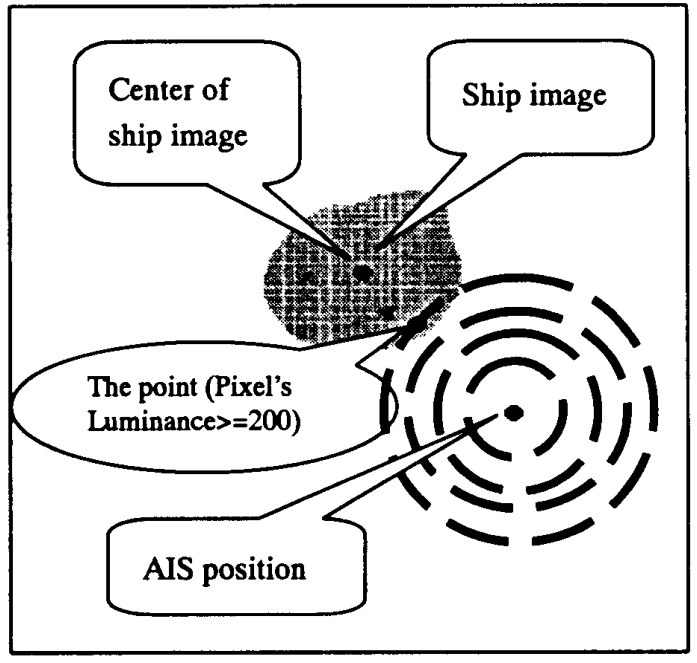

Fig.4 AIS position being outside the ship image

From AIS position as a center of circle, the point that pixel's luminance is $\mathbf{2 0 0}$ or more is automatically and continuously searched for by increasing the radius of the circle as shown by dashed line in Fig.4. When that point is found, the center of ship image is decided and the ship image is identified as a target as mentioned in 3.1.1.

\subsection{Tracks of the centers of ships' images}

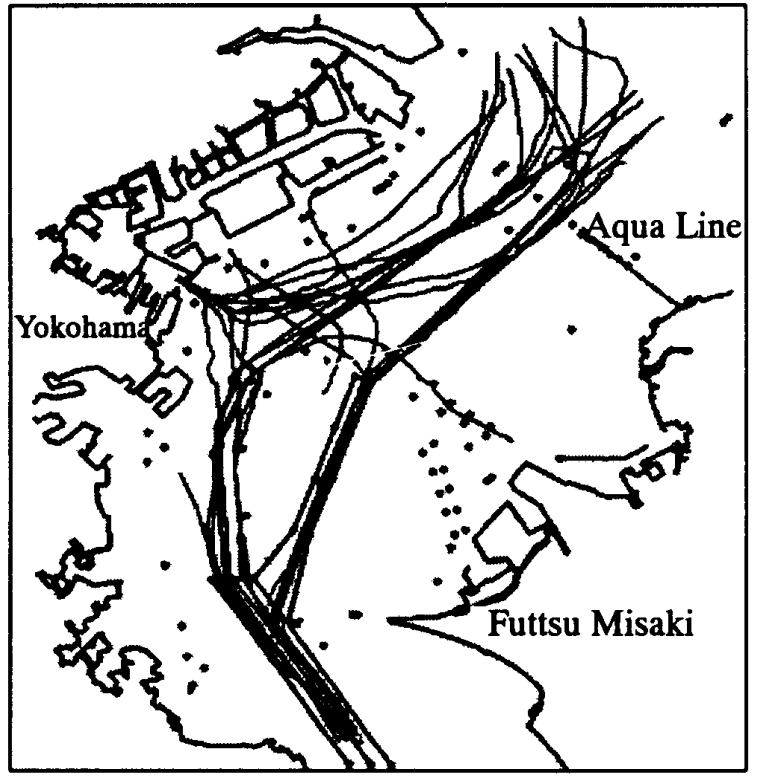

Fig.5 Tracks of the centers of ships' images obtained by AIS data on Oct. 7, 2004 
Based on the above procedure, 32 ships' images observed on Oct. 7, 2004 were automatically tracked using AIS data, and tracks of centers of ships' images are shown in Fig.5. From Fig.5, we can find that all ships' images were successfully tracked.

\subsection{Calculating difference between AIS position and center of ship image}

The difference between AIS position and center of ship image of one ship is shown in Fig.6 at intervals of one minute. The origin of axis is center of ship image, and the black circle indicates the difference in the range of Yokosuka radar station, and the black triangle expresses the difference in the range of Kawasaki radar station. Link between two circles or triangles shows change of difference in one minute. The line between two black squares means that the ship moved from one radar range to other radar range. This large jump of the difference is caused by different setting time of two radars and different size of ship image when the ship passes the boundary of two radar stations.

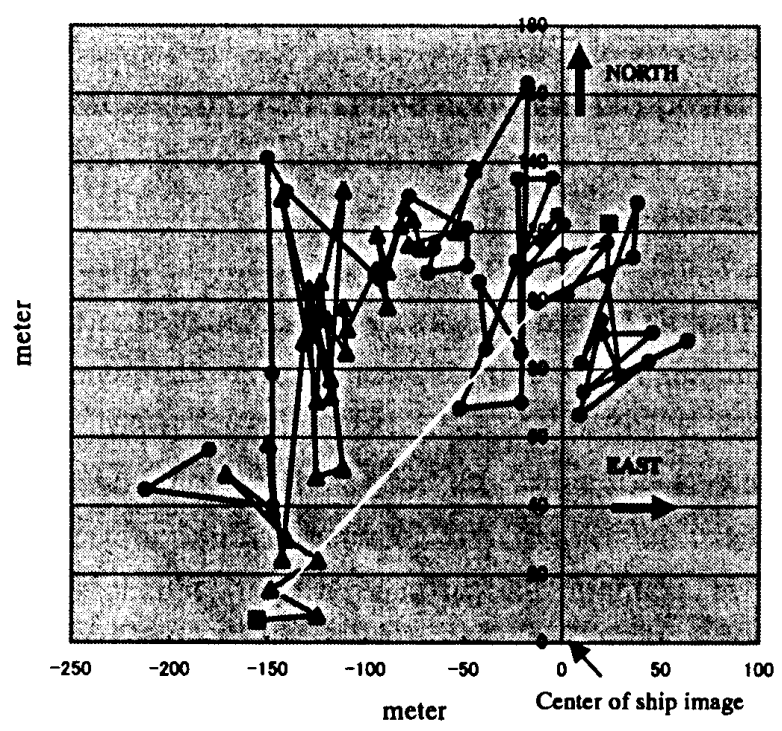

Fig.6 Difference between AIS position and the center of ship image

In addition, all differences between AIS positions and the centers of ships' images were calculated for 32 ships and plotted in Fig.7. The average of differences is calculated for each ship and the regression curve indicating relation between ship's length and average difference is drawn. It can be found that the average difference increases as ship's length increases.

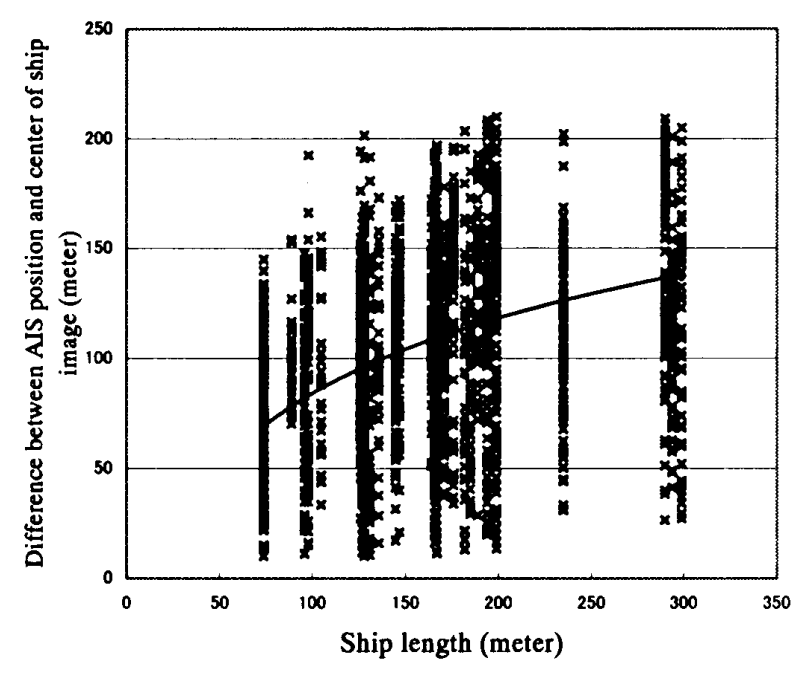

Fig.7 Difference between AIS position and center of ship image versus ship's length

\section{Estimation of ship's length by the size of ship image on radar screen}

Methods to estimate the ship's length based on the size of ship image on radar screen have been explained in former studies ${ }^{(2)(4)}$.

For improving the accuracy of estimating ship's length, the second visual observation was carried out from 10:00 to 17:30 on Oct. 7, 2004 (the first observation was carried out on Feb.15, 2003). Besides, AIS data from 00:00 to 10:00 on May 22 and 24 hours on Oct.7, 2004 were added up to estimate the ship's length, together with the ship images of radar observation.

\subsection{Formula for estimating ship's length based on the second visual observation and AIS data}

Comparing the size of ship image on radar screen with the ship's length confirmed with the Register Book, calculated by photographs or received from AIS data, the regression formula for estimating the ship's length can be obtained as same as described in the last two papers.

Based on the data of the second visual observation and AIS data (May 22 and Oct.7, 2004), two regression formulae for estimating ship's length in the range of Yokosuka radar station and in the range of Kawasaki radar station were calculated as shown in Fig.8 and Fig.9. In two figures, the lengths of ships are shown on the vertical axis, and sizes of ships' images 
at a distance of 5 miles from Yokosuka radar station and 4 miles from Kawasaki radar station are shown on the horizontal axis. The symbol $\Delta$ expresses the data of visual observation, and $x$ and $\square$ show the data of AIS. The second order approximation curves and their expressions, namely the regression formulae are also shown inside.

There were 147 vessels in total in calculating formula of ship's length in the range of Yokosuka radar station, and 100 vessels in the range of Kawasaki radar station in second observation.

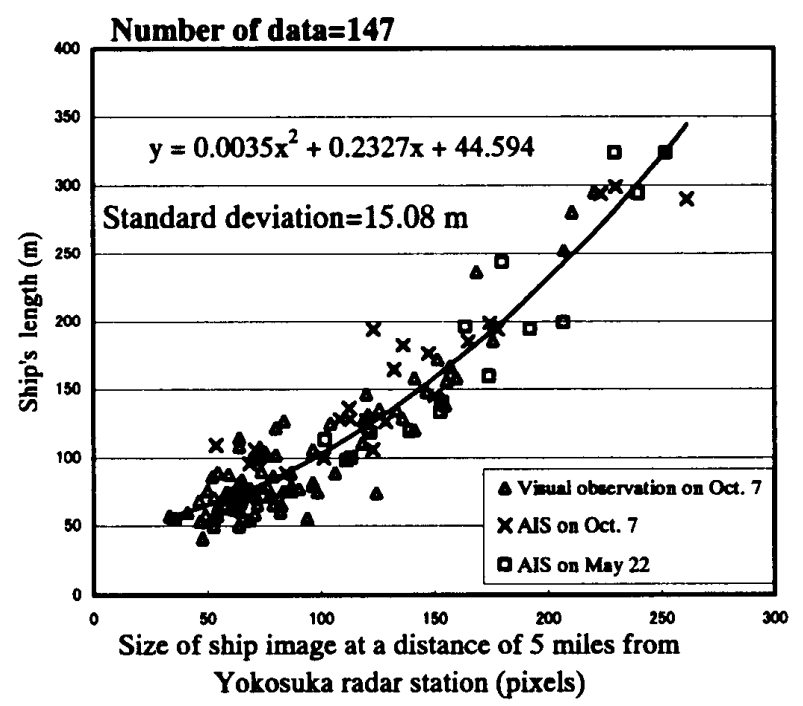

Fig.8 Formula for estimating ship's length in the range of Yokosuka radar station

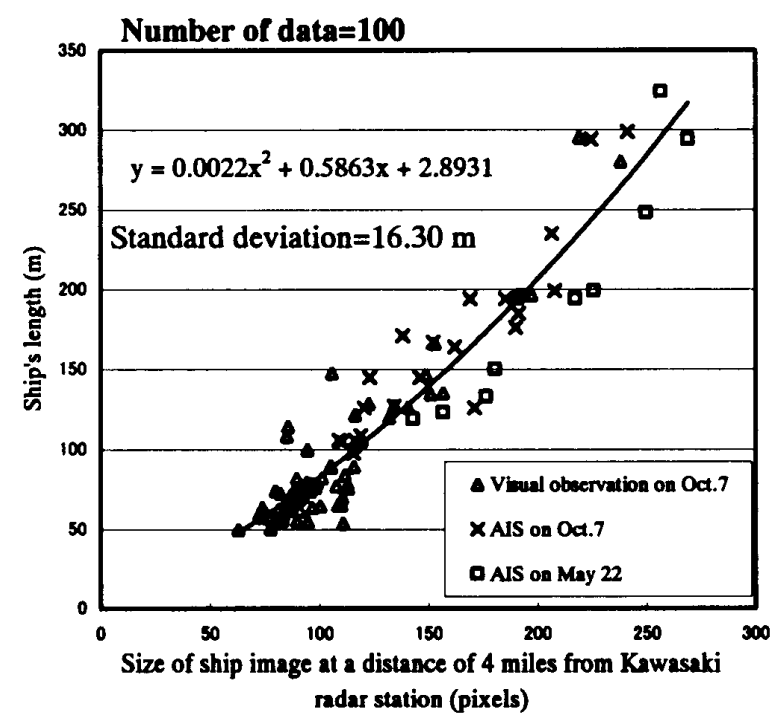

Fig.9 Formula for estimating ship's length in the range of Kawasaki radar station

\subsection{Evaluation of the formula for estimating ship's length}

Next, the accuracy of the formula for estimating ship's length is evaluated by using AIS data on May 27,2004 . The AIS data are plotted with the regression curves obtained by the first observation (Fig. 10) and the second observation (Fig.11) in the range of Yokosuka radar station.

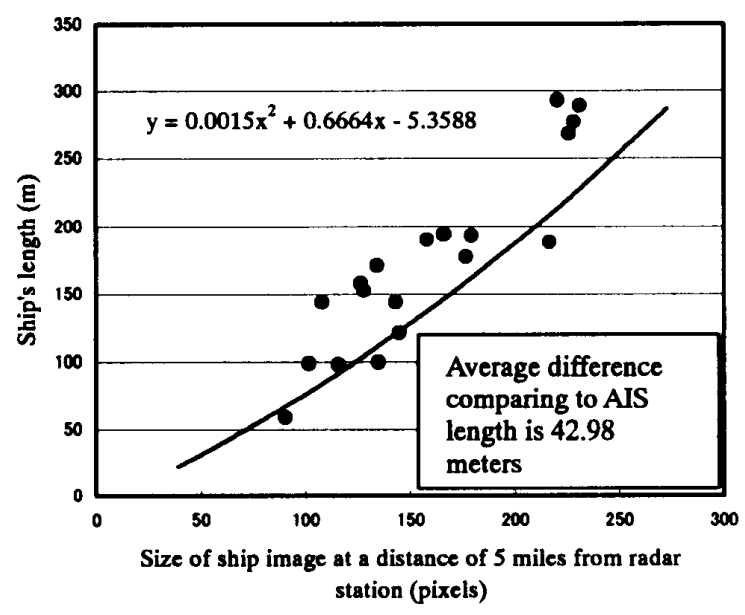

Fig.10 Evaluation of the formula for estimating ship's length in the first observation using AIS data on May 27, 2004 in the range of Yokosuka radar station

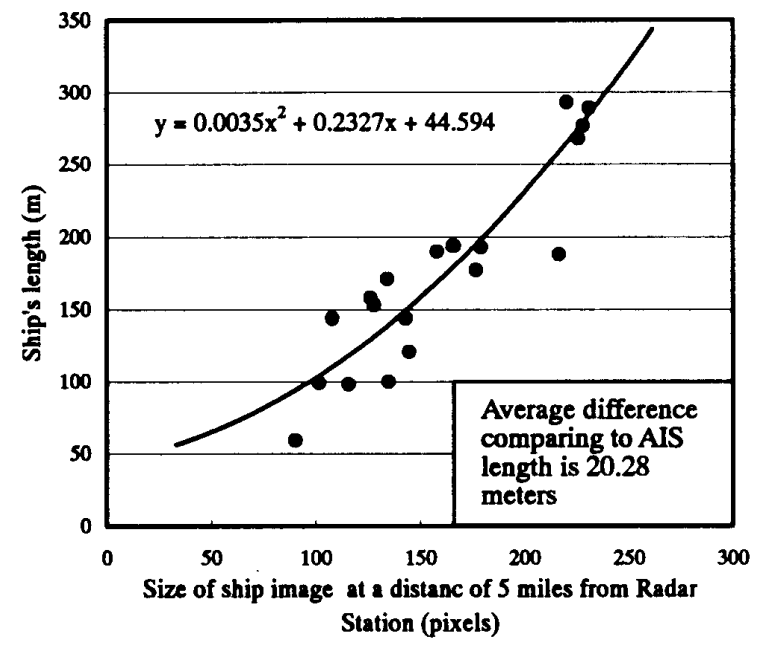

Fig.11 Evaluation of the formula for estimating ship's length in the second observation using AIS data on May 27, 2004 in the range of Yokosuka radar station

The average difference between ship's length by AIS data and ship's length calculated by the regression formula in the first observation is $\mathbf{4 2 . 9 8}$ meters as shown in Fig.10. However, the average difference in the second observation in Fig.11 is 20.28 meters. So it 
can be said that the accuracy of regression formula calculated in the second observation was greatly improved compared to that in the first observation.

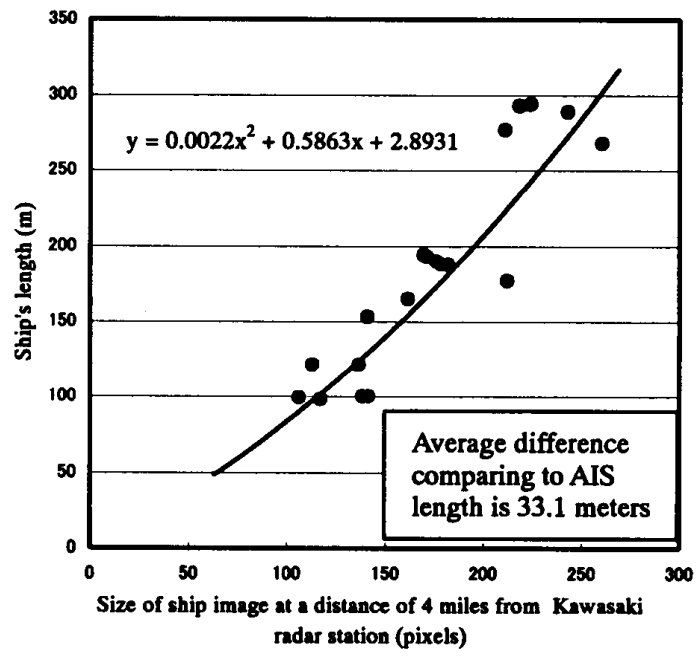

Fig.12 Evaluation of the formula of ship's length in the second observation using AIS data on May 27, 2004 in the range of Kawasaki radar station

By the same method, the average difference between ship's length by AIS data and ship's length calculated by the regression formula for estimating ship's length in the range of Kawasaki radar station was calculated as shown in Fig.12. The average difference is 33.1 meters, and we can find the regression formula for Kawasaki radar station is also accurate.

\section{Relation between ship's aspect and size of ship image}

In the previous section, the aspect of ship has not been considered when the regression formula of ship's length was calculated. For the purposes of knowing the relation between ship's aspect and size of ship image, the experiment was carried out on Nov.30, 2004 using the training ship "Shioji Maru" of TUMSAT. In addition, such the relation was also investigated using the ship with AIS navigating in Tokyo Bay on Oct.7, 2004.

\subsection{Results of Shioji Maru experiment}

The experiments were taken in two sites, position (1) was nearby exit of Nakanose Traffic Route, and position (2) was right of entrance of Uraga Suido Traffic Route. The distance and bearing to radar station are shown in Fig.13. During the experiments,
Shioji Maru was turned by 360 degrees at intervals of 45 degrees, keeping the same heading for 2 minutes. The aspect angle of Shioji Maru and the size of ship image on radar screen were recorded every 10 seconds.

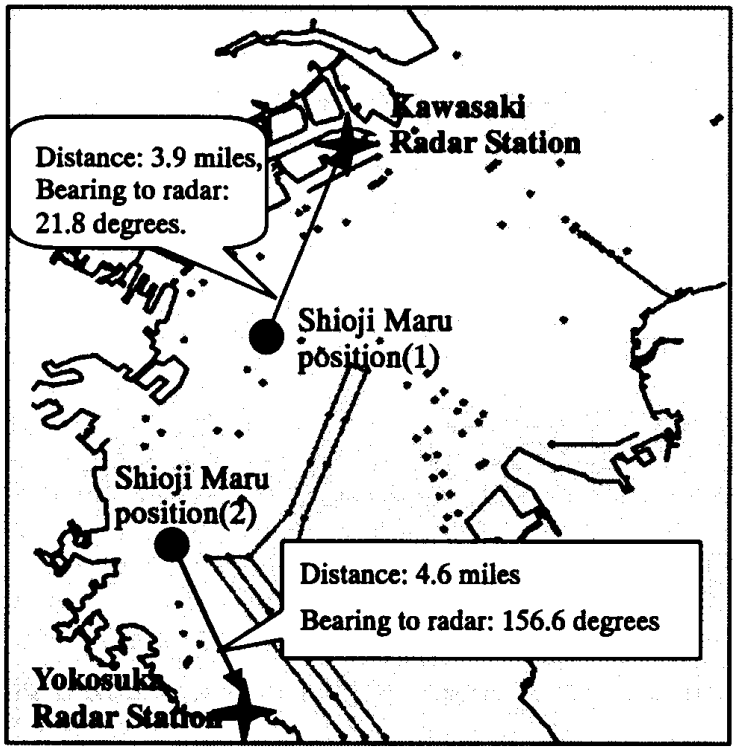

Fig.13 Positions of Shioji Maru in experiment

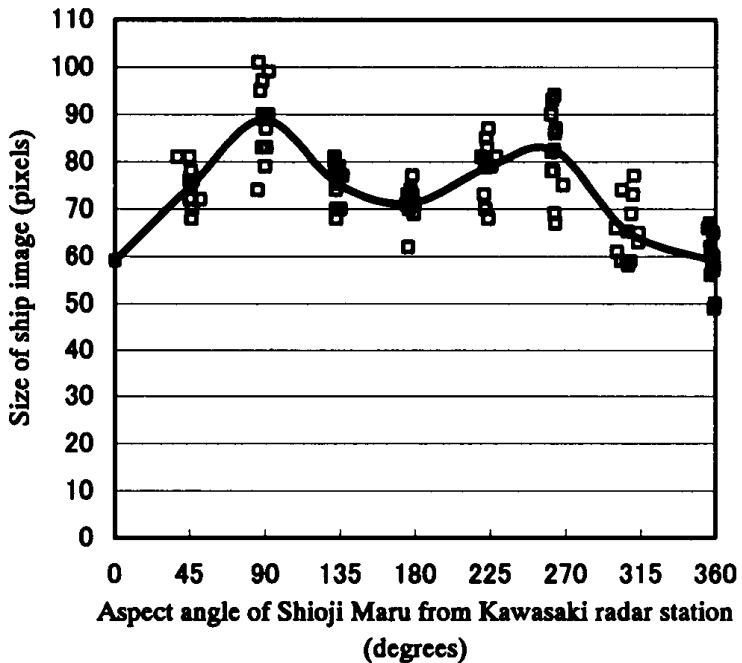

Fig.14 Size of ship image versus aspect angle of Shioji Maru in position (1)

The results of experiments are shown in Fig.14 for position(1) observed by Kawasaki radar station and in Fig.15 for position(2) observed by Yokosuka radar station. In both figures, bold curve connecting the average size of ship images at each aspect angle is drawn. It can be seen that the size of ship image takes minimum value at aspect angle of 0 degree and 180 degrees. On the contrary, it takes maximum value at 90 degrees and 270 degrees. In other words, the size of 
ship image is maximum when the ship is in abeam, and it is minimum when ship is in ahead and astern.

The experiments performed by Shioji Maru are not enough to take into account the aspect of a ship in estimating ship's length from the size of ship image, and more experiments in different ship type and size should be carried out.

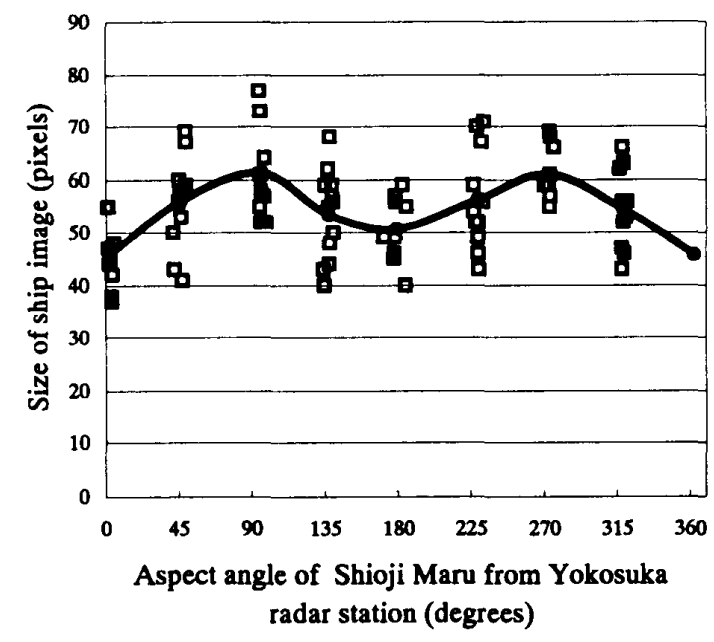

Fig.15 Size of ship image versus aspect angle of Shioji Maru in position (2)

\subsection{Results of the same ships sailing in different time within one day}

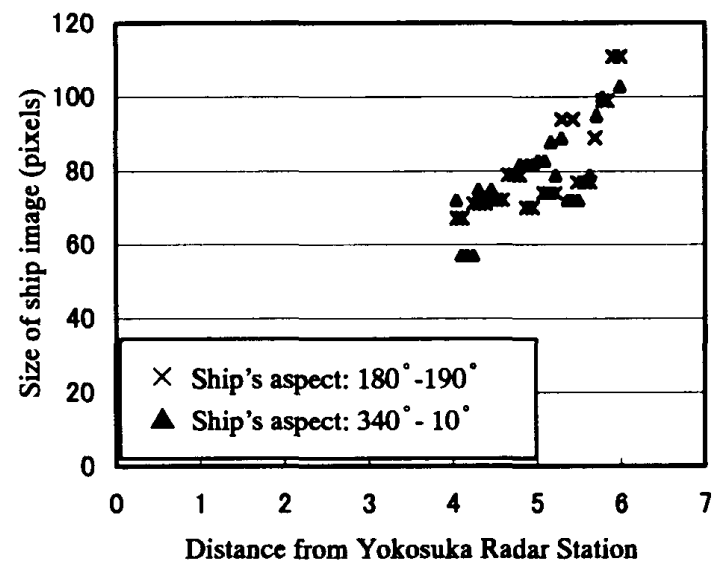

Fig.16 Change of size of ship image of the same ship sailing in different time within one day observed by AIS and Yokosuka radar station

In addition to the experiments of Shioji Maru, some same ships identified by AIS data were utilized to investigate the relation between the aspect and the size of ship image. The same ships identified by AIS data mean the ships sailed in different time and route in Tokyo Bay observed on Oct.7, 2004.

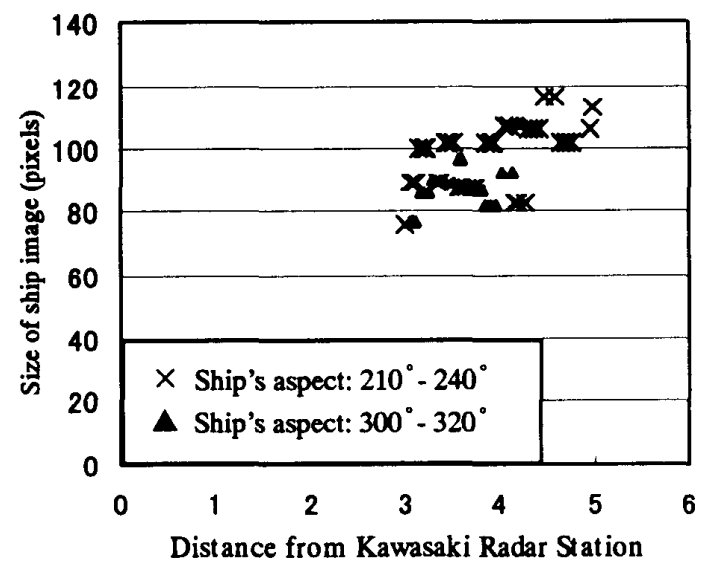

Fig.17 Change of size of ship image of the same ship sailing in different time within one day observed by AIS and Kawasaki radar station

One result of the same ships is shown in Fig.16 in the range of Yokosuka radar station and Fig.17 in the range of Kawasaki radar station. The $\mathrm{X}$-axis of coordinates shows distance between the ship and radar station and the $\mathrm{Y}$-axis indicates size of ship image. The marks $X$ and $\Delta$ express ship's aspect from radar station at different sailing time identified by AIS data.

In Fig.16 and Fig.17, we can find that size of ship image increases as distance increases. Simultaneously, it can be found in Fig. 16 because the change of the size of ship image is small in the aspect of 180-190 degrees and 340-10 degrees as shown in Fig.14 and Fig.15, the dispersion of plotted data is comparatively small. On the other hand, in Fig.17, we can find because the change of the size of ship image is large in aspect of 210-240 degrees and 300-320 degrees as shown in Fig.14 and Fig.15, the dispersion of plotted data is considerably large.

\section{Conclusion}

After integrating AIS (static and dynamic data) and the radar network system, the new methods for analyzing traffic flow in Tokyo Bay have been developed and verified in this study. That is,

(1) The center of ship image was automatically tracked using AIS position, then the difference between AIS position and the center of ship image was calculated.

(2) Ships' lengths were estimated based on the second visual observation and AIS data, and the regression 
formulae of estimating ship's length were evaluated by using another set of AIS data.

(3) Experiments using Shioji Maru were carried out to investigate the relation between ship's aspect from radar station and size of ship image; this relation was also investigated for the same ship sailing in different time identified by AIS data.

In brief, by comparing the ship image on the radar screen with AIS data, the new methods of analyzing traffic flow have been found. Then, the traffic characteristics in Tokyo Bay will be grasped more easily and accurately.

In the future, some studies will be carried out. First, the new methods for analyzing and evaluating traffic flow in Tokyo Bay will be developed using other functions of AIS data. Second, the AIS data will be integrated into radar image automatically in real time. Finally, the real-time web browsing of integrated radar image and AIS will be developed.

\section{References}

(1) Hagiwara, H., Ohtsu, K., Hayashi, S. and Shoji, R. (2002): Construction of Radar Network System for Observing Vessel Traffic in Tokyo Bay, Proceedings of 50th Academic Lectures of the Tokyo University of Mercantile Marine, pp.33-36.

(2) Shoji, R., Hagiwara, H., Ohtsu, K., Hayashi, S., Namie, H., Liu, S., Okano, T. (2003): Development of New Radar Network System for Observing and Analyzing Vessel Traffic in Tokyo
Bay, Proceedings of Asia Navigation Conference 2003, pp.67-74.

(3) Shun LIU, Hideki Hagiwara, Ruri Shoji, Hitoi Tamaru \& Tadashi Okano. Radar Network System to Observe \& Analyze Tokyo Bay Vessel Traffic, IEEE System, November 2004, ISSN 0885-8985, PP.3-11.

(4) Shun LIU, Tadashi Okano, Hideki Hagiwara, Ruri Shoji, Hitoi Tamaru \& Kohei Ohtsu. (2004): Study on Radar Network System for Observing Vessel Traffic in Tokyo Bay-II, -installation of Kawasaki Radar Station and AIS Receiving Station-, The Journal of Japan Institute of Navigation, Vol.111, pp.225-233.

\section{Question \& Answer} 计苨介（大量商船高専）：

航跡図より、レーダのつなぎ目で航跡が一点抜 けているように思えますが、原因はおわかりで しょうか?

\section{Shun LIU :}

航跡が一点抜けている原因は、船舶が川奇レー ダ局から横須賀レーダ局のエリアに移ったためで す。両レーダの動作タイミングの違いや、2つの レータ局からの距離が違うため船舶映像の大きさ が異なることなどが影繁しています。 